Pragmatic Case Studies in Psychotherapy, http://pcsp.libraries.rutgers.edu

Volume 15, Module 2, Article 1, pp. 99-104 [copyright by author]

Commentary on Moment-to-Moment Guidance of Clinical Interventions by AEDP's Healing-Oriented Transformational Phenomenology: Commentary on Vigoda Gonzalez's (2018) Case of "Rosa"

\title{
In the Shadows: On Meta-Awareness and Spiraling Effects in Psychotherapy_Comment on Nicole Vigoda Gonzalez and Diana Fosha
}

\section{LOUIS SASS ${ }^{\mathrm{a}, \mathrm{b}}$}

\author{
${ }^{a}$ Graduate School of Applied \& Professional Psychology, Rutgers-New Brunswick, NJ \\ ${ }^{\mathrm{b}}$ Correspondence regarding this article should be sent to: Louis Sass, Graduate School of Applied \& Professional \\ Psychology, 152 Frelinghuysen Road, Busch Campus, Piscataway, NJ 08854
}

Email: 1sass@gsapp.rutgers.edu

\begin{abstract}
I want to commend Nicole Vigoda Gonzalez (2018) for her sensitive, sophisticated, and successful treatment in the case of Rosa; and I want to commend Diana Fosha (2018) for the development of her phenomenologically sophisticated and effective Accelerated Experiential Dynamic Psychotherapy (AEDP) model, which Vigoda Gonzalez used. In this commentary I focus on a contrast between two different perspectives in Fosha's model, and implications for the case of Rosa. This contrast includes: (a) AEDP's focus on descriptive phenomenology, emphasizing the richness of each client's moment-to-moment, subjective experience, versus (b) Fosha's seemingly unqualified advocacy, in the Second Avatar version of AEDP, of the therapist explicitly encouraging meta-processing - that is, explicit self-awareness - as a final step of therapeutic healing. In my commentary I suggest that there seem to be certain limiting conditions for such advocacy. Specifically, I discuss how the clinical research literature argues that while meta-processing may be very helpful for some clients, for others-e.g., those employing the distancing defenses of derealization and depersonalization-meta-processing can be psychologically counterproductive. I conclude by re-emphasizing the importance of retaining a descriptive phenomenological perspective in AEDP.
\end{abstract}

Key words: depersonalization/derealization; schizoid personality; phenomenological description; Accelerated Experiential Dynamic Psychotherapy (AEDP); case study; clinical case study

It is a pleasure to comment on the case of "Rosa" by Dr. Nicole Vigoda Gonzalez (2018), and, in particular, on Dr. Diana Fosha's (2018) response to it. As befits the doubly meta-nature of my role (I will mostly be commenting on a commentary), I will focus on the issue of selfawareness or self-monitoring and on the associated "recursive spiraling processes" (p. 90) in psychotherapy that are discussed in Fosha's (2018) remarks. But before turning to that issue, I would like to register my profound respect for the compassionate, sensitive, and discerning work of the therapist, Vigoda Gonzalez, and for the illuminating commentary offered by Fosha-the 
Pragmatic Case Studies in Psychotherapy, http://pcsp.libraries.rutgers.edu

Volume 15, Module 2, Article 1, pp. 99-104 [copyright by author]

formulator of a distinctive approach to psychotherapy ("AEDP: Accelerated Experiential Dynamic Psychotherapy") that offers much to be admired.

\section{THE IMPORTANCE OF FOSHA'S “DESCRIPTIVE PHENOMENOLOGY" PERSPECTIVE}

Like Fosha, I am impressed with the skill and subtlety of Vigoda Gonzalez's work, and I view this as a highly successful treatment that is likely to have long-term effects in increasing the self-acceptance and self-integration as well as the vitality of the patient Rosa. Like Fosha, I would emphasize the importance of what Fosha terms "descriptive phenomenology" (p. 87), which refers to the attempt to stick, in one's therapeutic understanding and technique, as closely as possible to the actual, moment-to-moment nature of the patient's subjective life, in contrast with an approach (like that fostered by too-strict adherence to a therapy manual) that makes too many assumptions in advance about what is likely to occur and how the therapist should respond.

I am also strongly in agreement with Fosha's emphasis on "vitality-affects" (p. 92) which, of course, are necessarily rooted in bodily experience. In this respect, Fosha's approach is very much in sync with contemporary developments in phenomenological philosophy and phenomenological psychopathology (e.g., Gallagher 2005; Fuchs \& Schlimme 2009), as well as with the emphasis of a major (and increasingly dominant) approach in cognitive science, namely, the "4 Es" perspective (which emphasizes the embodied, enactive, embedded, and extended aspects of human experience; Menary 2010). The latter perspective, with its emphasis on bodily experience and activity, follows the writings of Edmund Husserl (e.g., 1989) and Maurice Merleau-Ponty (e.g., 2012) in recognizing the degree to which our subjective lives are grounded in, even constituted by, the lived-body — not only in its motoric capacities and sensory modalities but also in its needs and desires, and in the sense of aliveness that is inseparable from these latter (di Paolo \& De Jaegher 2015). Phenomenology, properly understood, does not constitute a focus on mind rather than body or behavior, nor on something essentially "inner" as opposed to material or intersubjective. It is a philosophy that recognizes the essential rootedness of conscious life not in the solus ipse of a detached "inner self," but in forms of subjectivity and selfhood grounded in the body and social world (Durt, Fuchs, Tewes 2017).

\section{LIMITING CONDITIONS ON THE GENERALITY OF FOSHA'S “SECOND AVATAR"}

There is an aspect of Fosha's commentary that I would like to call into question, however, and this is what seems to be (at least in her presently discussed commentary) her unqualified advocacy of fostering forms of meta-awareness or meta-processing about both one's experience and the process of healing itself. Specifically, what Fosha terms the "Second Avatar" (p. 92) of AEDP places the emphasis not just on the inspiration and processing of positive emotions and on the sense of safety and sharing that these imply (elements of AEDP's traditional "North Star" [p. 108]), but also on the supposed benefits of encouraging forms of metaawareness directly focused on the presence and nature of the invigorating affects and emotions associated with the healing process. This, I understand, is what Fosha means when she speaks of the "metaprocessing of transformational experience" (p. 90) and of "systematic experiential processing of transformational experiences, i.e. ....successive rounds of metaprocessing” (p. 
Pragmatic Case Studies in Psychotherapy, http://pcsp.libraries.rutgers.edu

Volume 15, Module 2, Article 1, pp. 99-104 [copyright by author]

93) - a process whereby the "experiential processing of transformational experiences (the new state 3)" becomes co-equal with the "experiential processing of emotional experience (state 2)" (p. 92). It is here, according to Fosha, that "AEDP's transformational phenomenology took a giant leap, with the increasingly detailed description of the different metatherapeutic processes, each with its own characteristic transformational affect" (p.`93).

The presumed benefits of focusing therapeutic attention on the process of change itself seems to be the key advantage claimed for AEDP's Second Avatar. In her commentary, Fosha states that "the positive affects that accompany transformational experiences" (p. 89) should be "attended to as carefully as [are] the negative affects of trauma" (p. 89. She writes: "focusing on the experience of transformation itself unleashes further rounds of transformation, through which positive changes can be powerfully consolidated, deepened, and expanded in a momentumgenerating spiral of healing" (p. 89); and indeed, she claims that "[p]rogressive rounds of metatherapeutic processing [will] lead to a nonlinear, nonfinite transformational spiral, an ever emergent upward movement... that fuels the system with more and more energy and vitality" (p. 89).”

The clinical import of this issue emerges at several points in Fosha's commentary when she delicately suggests that Vigoda Gonzalez - despite what is acknowledged to be the sensitive and highly effective nature of her therapeutic work - may nevertheless have missed a "huge opportunity" (p. 100) by not responding sufficiently (presumably, more directly or explicitly) to her client Rosa's statements about feeling enlivened, motivated, and filled with increased curiosity and desire. "But there is potential here for more," writes Fosha:

Surprise and excitement are transformational affects of enlivenment, denoting a transformational experience. What would have happened if Rosa's surprise and excitement had also been explicitly recognized, affirmed, focused on, and experientially processed? There may have been an even greater transformational impact than what the therapist already articulated (p. 97).

In a later passage, Fosha writes: "If the "transformational phenomena [had] been therapeutically engaged as systematically as the experiential work and the relational metaprocessing were, there is no telling what further broadening and building would have occurred" (p.. 102). Fosha's references and description of Rosa's clinical process indicate that Fosha views the course of treatment under discussion as reflecting an earlier version of her AEDP model (the "First Avatar" [p. 91]), one that was more "focused on the experiential processing of relational and emotional experience, and less focused on the meta-processing of transformational experience" (p. 90) - that is, more focused on paying attention to experiences of enlivening or energizing affects and appetitive urges that are associated with positive therapeutic change.

It is impossible to know whether Fosha is right or wrong in her speculations about a counter-factual-about what further growth and healing might have occurred if Vigoda Gonzalez had, at these points, turned the focus of the therapeutic dialogue more directly on the patient's revived sense of vitality and desire, so that these were more "explicitly recognized, affirmed, focused on" (p. 97). Perhaps Fosha is correct. I think it is important to remember, however, that there can also be certain dangers in explicitness and in the encouraging of self-consciousness. 
Pragmatic Case Studies in Psychotherapy, http://pcsp.libraries.rutgers.edu

Volume 15, Module 2, Article 1, pp. 99-104 [copyright by author]

Indeed, as discussed below, these latter can, in certain persons or at certain times, be as likely to foster forms of alienation as they are to encourage self-understanding and self-integration inherent in the ideals Fosha evokes when she speaks of "'This is me' revelations"-revelations that involve "an internal experience of coherence, of cohesion, of completion, of essence," a "new sense of self...integrated into a larger self" ( $p$ 94).

Perhaps the clearest examples of the potentially self-alienating dangers of selfconsciousness occur in persons with a largely schizoid personality orientation. I am using "schizoid" here in the manner of British Object-Relations theorists such as W.R.D. Fairbairn and Harry Guntrip — writers who view schizoid individuals not as devoid of emotional or interpersonal interests, but rather, as prone to adopting distancing defenses in order to avoid the anxieties and potential for painful loss that would occur if they allowed themselves to experience their emotional and interpersonal yearnings in a more spontaneous and authentic manner.

Fairbairn, writing of schizoid defenses, describes a characteristic "splitting of the ego" that involves a sense of being a purely mental self or subject, separated from both the body and the external world, as well as a feeling of "intense self-consciousness and a sense of looking on at oneself" (Fairbairn, 1954, pp. 29, 51). Guntrip speaks of "noninvolvement and observation at a distance without any feeling," and of experiencing life from a "free-floating position" (Guntrip 1969, p 18; see also Sass, 2017, Chapter 3, “The separated self”). For such persons, an explicit meta-awareness of some aspect of their own psychological being (of their thoughts, emotions, or bodily sensations) often serves as a way of further separating them from that aspect - of turning that aspect into a kind of distanced quasi-object rather than an experience or state of being that they truly inhabit or with which they deeply identify in a psychological sense.

I have mentioned the schizoid orientation. The issue I raise is of relevance, however, to more than this one exceptional subset of the human population, given that distancing defenses (involving derealization and depersonalization) are in fact part of the general psychological repertoire of most human beings. (Research shows that depersonalization is a very common psychiatric symptom [Simeon 2004].) It would be completely unwarranted to argue that conscious awareness or more targeted psychological processing necessarily brings on dissociative forms of defense, or that its impact is usually in the service of self-alienation rather than self-integration. It would, however, also be problematic to ignore this potential outcome. Here an aesthetic analogy may be of some relevance; for it is, I think, well recognized that too explicit a statement or expression of a crucial theme or dimension in a work of art, such as a novel or a painting, will often have the effect of undermining the impact, and particularly the emotional force, of that theme or dimension.

Here one might also recall William James's (1981/1890, p 237) famous criticism concerning the limits of introspectionist awareness, which he compared to an attempt to turn up the gas quickly in order to see how the darkness looks: there can indeed be times when too direct a focusing on something may be futile or even counter-productive, serving less to illuminate something than to rob it of its essence. The interpersonal or psychotherapeutic equivalent of this phenomenon can occur when one's interlocutor, or perhaps one's therapist, says too explicitly (or perhaps in too jargon-ridden a way), or simply focuses too much attention on, what might better have been left to operate in a more subterranean, atmospheric, or darkly somatic fashion. 
Pragmatic Case Studies in Psychotherapy, http://pcsp.libraries.rutgers.edu

Volume 15, Module 2, Article 1, pp. 99-104 [copyright by author]

As in life in general, so in psychotherapy, the most meaningful and impactful moments should sometimes be allowed to stay in the shadows. Indeed we must remember that spirals (like circles) can be vicious as well as benign; that there is always the danger that a spiraling-upward (into higher or more explicit levels of self-awareness) may lead to a state of removal and selfdistancing rather than to an experience of greater integrity.

\section{RETURNING TO THE DESCRIPTIVE PHENOMENOLOGY PERSPECTIVE}

I would suggest, then, that it is possible that Vigoda Gonzalez might actually have shown a certain spontaneous wisdom in not commenting too directly on the rise in vitality affects of her patient Rosa, lest her therapeutic intervention, precisely in its overly explicit or overly "meta-“ nature, risk undermining the spontaneity or felt authenticity of the affective experience itself. This, of course, pertains to certain moments in a long and rich course of therapy. It is worth asking, however, whether these particular instances might hold some broader implications for what Fosha calls the Second Avatar of her AEDP approach: suggesting, in particular, that advocacy of a meta-oriented approach might need to be tempered with consideration of the counter-productive potential "metaprocessing" may have, at least with certain patients or at

particular moments of a therapeutic process. Such questioning strikes me as being very much in the spirit of Fosha's own favored vision of AEDP, which strives to eschew overgeneralization and to be maximally sensitive to the nuances of the individual client and the particular therapeutic moment. I would hope that concern about such risks be allowed to enhance the rich, moment-to-moment, and "descriptive phenomenological" implementation of AEDP's Second Avatar.

\section{REFERENCES}

Di Paolo, E.A. \& De Jaegher, H. (Eds.) (2015). Toward an embodied science of subjectivity: Widening the scope of social understanding research. Frontiers of Psychology, 6: 234. doi: $10.3389 /$ fpsyg.2015.00234

Durt, C., Fuchs, T., \& Tewes, C. (Eds.) (2017). Embodiment, enaction, and culture: Investigating the constitution of the shared world. Cambridge, MA: MIT Press.

Fairbairn, W.R.D. (1954). An object-relations theory of the personality. New York: Basic Books. Fosha, D. (2018). Moment-to-moment guidance of clinical interventions by AEDP's healingoriented transformational phenomenology: Commentary on Vigoda Gonzalez's (2018) Case of "Rosa." Pragmatic Case Studies in Psychotherapy, 14(2), Article 1, 87-114. Available: http://pcsp.libraries.rutgers.edu http://dx.doi.org/10.14713/pcsp.v14i2.2038

Fuchs, T, Schlimme, JE, (2009). Embodiment and psychopathology: A phenomenological perspective. Current Opinion in Psychiatry 22(6): 570-575.

Gallagher, S. How the body shapes the mind. Oxford University Press 2005

Guntrip, H. (1969). The schizoid personality and the external world," in Schizoid phenomena, object-relations, and the self. New York: International Universities Press.

Husserl, E. Ideas Pertaining to a Pure Phenomenology and to a Phenomenological Philosophy. Second Book. Studies in the Phenomenology of Constitution. Trans. Richard Rojcewicz and André Schuwer. Dordrecht: Kluwer Academic Publishers, 1989, 
Sass, L.

Pragmatic Case Studies in Psychotherapy, http://pcsp.libraries.rutgers.edu

Volume 15, Module 2, Article 1, pp. 99-104 [copyright by author]

James, W. (1981, orig 1890). The principles of psychology. Cambridge MA: Harvard University Press.

Menary, R. Introduction to the special issue on 4E cognition. Phenomenology and the cognitive sciences (2010) 9:459-463.

Merleau-Ponty, Maurice. Trans: Donald Landes. Phenomenology of Perception (London: Routledge, 2012)

Sass, L. (2017). Madness and modernism: Insanity in the light of modern art, literature, and thought: Revised edition. Oxford UK: Oxford University Press.

Simeon D (2004). "Depersonalisation Disorder: A Contemporary Overview". CNS Drugs. 18 (6): 343-354. doi:10.2165/00023210-200418060-00002. PMID 15089102.

Vigoda Gonzalez, N. (2018). The merits of integrating accelerated experiential dynamic psychotherapy and cultural competence strategies in the treatment of relational trauma: The case of "Rosa." Pragmatic Case Studies in Psychotherapy, 14(1), Article 1, 1-57. Available: http://pcsp.libraries.rutgers.edu http://dx.doi.org/10.14713/pcsp.v14i1.2032 